\title{
SOBRE A AUTONOMIA NA DEFINIÇÃO DA TEMPORALIDADE LIVRE DOS MÉDICOS
}

Recebido em: 19/03/2020

Aprovado em: 14/09/2020

Licença:@) (1) @

\author{
Darli Chahine Baião ${ }^{1}$ \\ José Clerton de Oliveira Martins ${ }^{2}$ \\ Universidade de Fortaleza (UNIFOR) \\ Fortaleza - CE - Brasil
}

Francisco Welligton de Sousa Barbosa Junior ${ }^{3}$

Universidade de Aveiro (UA)

Aveiro - Portugal

Cynthia de Freitas Melo 4

Universidade de Fortaleza (UNIFOR)

Fortaleza - CE - Brasil

RESUMO: Objetivou-se compreender a autonomia de médicos recém-especialistas na definição de suas temporalidades livres e as possíveis repercussões nos diferentes âmbitos de suas vidas. Por meio de uma pesquisa exploratória, de cunho qualitativo, sete médicos especialistas responderam a um roteiro de entrevista semiestruturada e um pressuposto de tempos de atividades, compreendidos através da análise de conteúdo de Bardin. Observou-se que os médicos compreendem o tempo livre em oposição ao trabalho e afirmam não o possuir. Destacam ainda que a existência de tempo livre é decorrência da especialidade escolhida, menor carga de trabalho, conclusão da residência e decisão pessoal. Conclui-se que a falta de tempo é uma característica marcante que merece ser melhor refletida no que se refere às consequências dessa realidade sobre o profissional, sua saúde e suas relações sociais.

PALAVRAS-CHAVE: Médicos. Tempo Livre. Autonomia.

\footnotetext{
${ }^{1}$ Doutoranda e Mestra em Psicologia pela Universidade de Fortaleza. Graduada em Psicologia pela mesma instituição. Membro do Laboratório de Estudos sobre o Trabalho (LET), do Programa de PósGraduação em Psicologia da Universidade de Fortaleza.

${ }^{2}$ Doutor em Psicologia pela Universidade de Barcelona. Professor do Programa de Pós-Graduação em Psicologia da Universidade de Fortaleza (UNIFOR), Fortaleza-CE/Brasil. Coordenador do OTIUM/Grupo de Estudos Multidisciplinares sobre Ócio e Tempo Livre do Programa de Pós-Graduação em Psicologia da Universidade de Fortaleza.

${ }^{3}$ Doutorando em Estudos Culturais pela Universidade de Aveiro. Mestre em Literatura pela Universidade de Évora e em Psicologia pela Universidade do Minho. Membro do OTIUM/Grupo de Estudos Multidisciplinares sobre Ócio e Tempo Livre, do Programa de Pós-Graduação em Psicologia da Universidade de Fortaleza, e do Núcleo de Estudos em Cultura e Ócio, do Programa Doutoral em Estudos Culturais da Universidade de Aveiro.

${ }^{4}$ Doutora em Psicologia pela Universidade Federal do Rio Grande do Norte. Professora do Programa de Pós-Graduação em Psicologia da Universidade de Fortaleza (UNIFOR), Fortaleza-CE/Brasil. Coordenadora do Laboratório de Estudos e Práticas em Psicologia e Saúde (LEPP-Saúde), do Programa de Pós-Graduação em Psicologia da Universidade de Fortaleza.
} 


\section{ABOUT THE AUTONOMY OF THE DEFINITION OF FREE TIME OF DOCTORS}

ABSTRACT: This study aimed to understand the autonomy of newly doctors experts in defining their free time frames and its possible repercussions in different aspects of your life. From an exploratory research, seven doctors experts answered a semistructured interview guide and an assumption activity times, understood by a qualitative bias by Bardin content analysis. It was observed that doctors understand free time in opposition to the work. They say they don't have free time and want to own it to invest more in them. Also underscore that the existence of free time is due to the type of specialty choice, lower workload, completion of the residence and personal decision. We conclude that lack of time is a remarkable feature that deserves to be better reflected as regards the consequences of this reality on the professional, their health and their social relations.

KEYWORDS: Doctors. Free Time. Autonomy.

\section{Introdução}

A medicina nos tempos atuais configura-se como uma profissão de grande sucesso e reconhecimento, alimentada por uma notória capacidade de persistência ao longo da formação profissional, que demora muitos anos, da graduação às subespecializações. Apresenta-se também como uma profissão na qual o mundo do trabalho se funde e se confunde com a vida pessoal, podendo-se inferir que, em parte, o sucesso da carreira médica está relacionado à adesão dos membros à vida profissional em sobreposição a sua vida pessoal (MACHADO, 1997).

Apesar disso, muitas são as recompensas psicológicas inerentes à profissão médica, como a consciência de ter o poder para aliviar a dor, salvar vidas, oferecer diagnósticos; bem como sentir-se competente, ensinar, aconselhar, ser reconhecido e receber gratidão. Fatores que servem como reforçadores para o profissional (NOGUEIRA-MARTINS, 2003).

Observa-se, portanto, que ser médico é dignificante e exige sacrifícios (CONSELHO FEDERAL DE MEDICINA [CFM], 2007), e, apesar da crise econômica 
nacional, a medicina permanece como uma profissão que proporciona inúmeras possibilidades de realização material, intelectual e emocional (NOGUEIRA-MARTINS, 2003), mas que apresenta muitos desafios e dificuldades que não podem ser ignorados.

Em todo o mundo, nas diferentes categorias profissionais, as reivindicações pela diminuição da jornada de trabalho, e por mais tempo disponível para o lazer e o descanso, proliferaram-se mais do que as relacionadas à melhoria nas condições de trabalho (MACHADO, 1997). Inclusas nessa sobrecarga exaustiva, observa-se que a classe médica, apesar do "status" diferenciado em relação às outras profissões da área da saúde, também vem se submetendo a processos de assalariamento e relações de mercado autônomas e anômalas (DONNANGELO, 1971).

Confirmando essa realidade, Clever (1990) aponta que os médicos trabalham mais que a maioria das pessoas (15 horas por semana a mais que outros profissionais); tiram menos tempo de férias (4 semanas/ano) do que outros profissionais (8 semanas/ano) e trabalham um maior número de anos do que a população geral. Trindade e Lautert (2010) ressaltam as múltiplas atividades exercidas frequentemente pelos médicos, que se dedicam a diversas demandas devido à possível flexibilidade de horários. Já Magalhães et al. (2014), em seu estudo com médicos, enfatizam a sobrecarga de trabalho pelo viés do excesso de atividades desempenhadas, que, muitas vezes, são maiores do que a capacidade do profissional, o que pode desencadear a carga excessiva de trabalho.

Este desgaste profissional vivenciado pelo médico também tem repercussões na sua vida pessoal, indicando que o seu trabalho afeta suas relações interpessoais devido à falta de tempo, sobrecarga de trabalho e privação de sono (CFM, 2007). Retrato este de uma vida sem pausa poderia afirmar Crary (2015). Deste modo, o lazer e o tempo livre para si e para os outros são afetados quando os profissionais são submetidos a um 
regime extenuante de trabalho (HAN, 2018), comprometendo suas relações sociais estabelecidas e sua percepção de liberdade e autonomia.

Para acompanhar a lógica desse sistema capitalista, grande número de médicos exercem a função de plantonista, modalidade fatigante não só pelas condições de trabalho, como também pela baixa remuneração e carência de recursos tecnológicos (CFM, 2007).

Em outras palavras, muitos médicos tomam para si horas intermináveis de plantões em busca de garantir o sustento da família, manter um padrão social alto ou por uma aposentadoria digna. Sem vínculos empregatícios formais, ou com vínculos frágeis, não possuem um futuro "certo", como retribuição satisfatória dos anos dedicados à sociedade, que lhes possibilitem desfrutar dos anos derradeiros de suas vidas com a família (CFM, 2007).

Contempla-se, contudo, que, se os empenhos laborais promovem benefícios monetários, os não-monetários parecem longe de ocorrer, pois, como lembra Csikszentmihalyi (1999), ter mais dinheiro para usufruir não se traduz, necessariamente, em bem-estar subjetivo pleno.

No entanto, ainda segundo este autor, apesar da evidência da sutilidade da relação entre riqueza material e a felicidade, grande parte das pessoas ainda se apega à noção de que seus problemas seriam resolvidos com o simples fato de uma melhor situação econômica/financeira. Mas quando a questão do dinheiro não parece ser o ponto principal, outros fatores entram em cena, entre eles a falta de tempo.

Para que seja possível iniciar uma discussão sobre o tempo e a medicina, faz-se necessária uma apresentação do conceito de tempo e autonomia utilizados e diversos entrelaçamentos que perpassam essas temáticas. 
O tempo não é somente um construto definido socialmente; é também uma categoria da ordem do subjetivo, na qual seus sentidos e significados são elaborados por quem o vivencia (MARTINS, 2013, 2016, 2018; FRANCILEUDO; MARTINS, 2015; AQUINO; MARTINS, 2007). Assim, desde que o homem resolve medir o tempo cotidiano e quantificar o tempo social, o elemento temporal passou por metamorfoses significativas até se tornar uma mercadoria com valor econômico (MARTINS, 2013; (FRANCILEUDO; MARTINS, 2015; AQUINO; MARTINS, 2007).

Em um espectro que vai desde um tempo totalmente condicionado até um mais autocondicionado, e, consequentemente, com maior autonomia de escolha, Munnè (1980) e Gurgel (2017) apresentam uma tipologia do tempo social que se divide em: tempo psicobiológico, tempo socioeconômico, tempo sociocultural e tempo livre. Dentre esses tempos, o tempo livre representa a quarta categoria e se refere às ações que ocorrem sem uma necessidade externa, devendo ser marcado pelo uso do tempo com total autonomia e de maneira criativa (AQUINO; MARTINS, 2007; FRANCILEUDO; MARTINS, 2015; MARTINS, 2008, 2013, 2016).

Observa-se, entretanto, que, algumas vezes, seu uso é dirigido ao consumo esvaziado de sentidos subjetivos, corrompendo-o, mercantilizando-o e empobrecendo-o de significados. Desta forma, na contemporaneidade, uma experiência no tempo livre percebida na vivência subjetiva pode denotar uma experiência esvaziada, pela falta de autonomia ou de significado, e até mesmo não significar descanso, desenvolvimento pessoal ou divertimento (MARTINS, 2008, 2013, 2016, 2018; FRANCILEUDO; MARTINS, 2015; AQUINO; MARTINS, 2007).

Em meio aos diversos significados da palavra autonomia, utilizou-se a ideia que diz respeito à noção de possibilidade de escolha de ser e fazer, relacionada ao uso da liberdade, como a autonomia da vontade, o poder de escolher ou decidir o próprio 
destino. Deste modo, é válido ressaltar que, embora existam outras formas de autonomia, como a autonomia no trabalho, utiliza-se aqui a autonomia ética: autonomia enquanto exercício da subjetividade e propriedade constitutiva da pessoa humana (SEGRE; SILVA; SCHRAMM, 1998).

Ressalta-se que no presente artigo não se considerou a autonomia como um estado de liberdade absoluta, mas numa perspectiva dialética, na qual a autonomia é sempre o exercício em que a liberdade é perpassada com o seu contrário, com as leis e determinações, sendo um espaço, muitas vezes, marcado pela heteronomia (SEGRE; SILVA; SCHRAMM, 1998).

Assim, a possibilidade de escolha marca o alicerce da autonomia, sendo fundamental que existam possibilidades. Caso exista um único caminho a seguir, não se faz possível o exercício da autonomia (CHAUÍ, 1995).

Nesse sentido, a autonomia também está intrinsecamente relacionada à forma como o sujeito estabelece o uso do tempo livre, no momento em que o seu exercício tem como uma de suas precondições a liberdade.

Por outro lado, a noção de tempo livre na atualidade afasta-se da ideia de autonomia, e é marcada por uma compreensão equivocada, na qual predomina o traço imperativo da atividade laboral. O tempo livre, no cenário atual, é "uma referência temporal e implica uma divisão da 'unidade' do tempo que se opõe ao tempo de trabalho" (AQUINO; MARTINS, 2007, p. 490).

Em relação aos médicos, é na corrida de status social, em resposta ao estatuto idealizado ou apenas de sobrevivência, que muitos se veem na condição de investir profissionalmente em diversas frentes, acumulando horários e abrindo mão da vivência de tempos fundamentais que poderiam (ou deveriam) ser dedicados ao descanso, ao lazer e à família (FRASQUILHO, 2005). 
Assim, é entre o caos das necessidades econômicas e existenciais que o homem contemporâneo se vê dividido: de um lado as obrigações impostas por suas atividades profissionais e, do outro, o desejo de se libertar dessas tarefas, para, assim, poder usufruir um tempo para si (MARTINS, 2008, 2013, 2016, 2018; FRANCILEUDO; MARTINS, 2015; AQUINO; MARTINS, 2007).

A partir dessas reflexões, o presente estudo tem como objetivo compreender a autonomia de médicos recém-especialistas na definição de suas temporalidades livres e suas possíveis repercussões nos diferentes âmbitos de sua vida.

\section{Método}

\section{Tipo de Estudo}

O presente estudo trata-se de uma pesquisa exploratória e descritiva, de abordagem qualitativa, que pretende conhecer e aprofundar-se sobre essa temática pouco estudada.

\section{Instrumentos}

Utilizaram-se os seguintes instrumentos para coleta de dados. Foi usado um roteiro de entrevista semiestruturada elaborado pelos autores com perguntas norteadoras sobre a compreensão e uso do tempo livre e as atividades desempenhadas durante a semana: (1) O que você compreende por tempo livre? (2) Você tem tempo livre ao longo da semana e final de semana? (3) O que você faz no seu tempo livre? (4) Que aspectos do seu trabalho interferem no seu tempo livre? (5) Você considera que tem tempo livre na hora do seu trabalho? e (6) Você gostaria de ter mais tempo livre? Para realizar o quê? 
Também foi usado um pressuposto de tempos de atividades (agenda diária), que permite dimensionar as horas diárias com a finalidade de descrever as atividades realizadas por hora em um dia escolhido e o grau de autonomia sentido pelo participante, sendo 1 a menor sensação e 4 a maior. Na aplicação do instrumento utilizou-se o conceito "sentir-se livre" para que fosse possível chegar a uma ideia compreensível para os participantes do conceito de autonomia utilizado no artigo.

\section{Participantes}

Contou-se com a participação de sete médicos recém-especialistas atuantes em Fortaleza e Região Metropolitana, com número estabelecido por critério de saturação, convidados por meio da técnica de bola de neve a partir de sujeitos previamente conhecidos.

Como critério de inclusão estabeleceu-se que os participantes deveriam: 1) residir em Fortaleza; 2) ser formado em Medicina; 3) ser especialista e não estar fazendo algum tipo de residência; e 4) ter terminado a residência há no máximo 5 anos. Contempla-se que as entrevistas foram realizadas de forma individual, com auxílio de gravador.

Quanto ao perfil sociodemográfico dos sete sujeitos entrevistados, quatro são do sexo feminino e três do sexo masculino, com faixa etária entre 28 e 31 anos, sendo dois solteiros, um noivo e quatro casados.

\section{Procedimentos Éticos e de Coleta de Dados}

Considerando-se os aspectos éticos referentes a pesquisas envolvendo seres humanos, a pesquisa foi aprovada pela Comissão de Ética em Pesquisa da UNIFOR, sob o protocolo de $n^{\circ}$ 913.866, em 01/12/2014. Em seguida, os participantes indicados pela 
Bola de Neve foram contatados individualmente para agendamento dos encontros. Estes foram informados previamente dos objetivos e procedimentos do estudo, sendo solicitado, ainda, que assinassem o Termo de Consentimento Livre e Esclarecido (TCLE). Quanto às entrevistas, estas ocorreram de forma individual, com uso de gravador, garantindo o anonimato da sua colaboração e a confidencialidade de suas respostas.

\section{Análise dos Dados}

As entrevistas foram compreendidas através de Análise de Conteúdo de Bardin (2011), dividindo o conteúdo em categorias e contabilizando as frequências de Unidades de Contexto Elementar (UCEs); e a Agenda Diária foi interpretada através de análise qualitativa (análise dos discursos) e análise quantitativa (estatística descritiva dos dados).

\section{Resultados e Discussão}

\section{Perfil Profissional dos Participantes}

Ao traçar o perfil de atuação profissional dos participantes, observa-se que suas principais atividades laborais são: plantão $(f=06)$, consultório próprio $(f=02)$, clínica particular $(f=02)$, hospital público $(f=05)$, atividade docente $(f=01)$, trabalho no interior do estado $(f=03)$, Clínica popular/Policlínica/UPA $(f=03)$ e outros $(f=02)$, podendo cada médico contemplar mais de uma atividade. Sobre a residência médica, a maioria $(f=04)$ fez clínica médica, e os demais apresentaram especialidades distintas, tendo apenas um participante com mais de uma residência. Os dados detalhados por participantes podem ser observados na (TABELA 1). 
Tabela 1: Perfil profissionais dos participantes

\begin{tabular}{|c|c|c|c|c|c|}
\hline $\mathbf{P}$ & Sexo & Idade & Residência & $\begin{array}{l}\text { Conclusão } \\
\text { residência }\end{array}$ & Atividades \\
\hline $\mathrm{P} 1$ & $\mathrm{~F}$ & 30 & Nefrologia & 2014 & $\begin{array}{l}\text { Plantão, Clínica particular, Policlínica e } \\
\text { no interior (hospital público). }\end{array}$ \\
\hline P2 & M & 30 & $\begin{array}{l}\text { Clínica médica } \\
\text { Reumatologia }\end{array}$ & $\begin{array}{l}2012 \\
2014\end{array}$ & $\begin{array}{l}\text { Plantão, Consultório próprio e atua em } \\
\text { dois hospitais públicos (concursado e } \\
\text { contratado). }\end{array}$ \\
\hline P3 & $\mathrm{F}$ & 29 & Dermatologia & 2012 & $\begin{array}{l}\text { Plantão, Consultório próprio, Atividade } \\
\text { docente, prestação de serviços em um } \\
\text { sindicato e atua no interior (hospital } \\
\text { público). }\end{array}$ \\
\hline P4 & M & 31 & Clínica médica & 2014 & $\begin{array}{l}\text { Plantão atua em hospital público } \\
\text { (preceptor) e hospital privado. }\end{array}$ \\
\hline P5 & M & 28 & Clínica médica & 2014 & $\begin{array}{l}\text { Plantão e contratado de um hospital } \\
\text { público. }\end{array}$ \\
\hline P6 & $\mathrm{F}$ & 28 & Clínica médica & 2014 & $\begin{array}{l}\text { Plantão e Unidade de Pronto } \\
\text { Atendimento (UPA). }\end{array}$ \\
\hline P7 & $\mathrm{F}$ & 30 & Patologia & 2014 & $\begin{array}{l}\text { Atua exclusivamente em uma clínica } \\
\text { particular. }\end{array}$ \\
\hline
\end{tabular}

Contempla-se que quase todos os participantes $(f=06)$, dentre outras atividades, realizam plantão, confirmando os dados do Conselho Federal de Medicina (2007), que ressaltam a grande quantidade de médicos que trabalham em diversos locais, prioritariamente em plantões exaustivos e infestos, sendo esta a forma mais estressante de trabalho: fisicamente cansativo e emocionalmente desgastante (GOLDENSTEIN, 2011).

\section{Análise dos Discursos dos Médicos}

O corpus geral analisado foi constituído por sete entrevistas, Unidades de Contexto Inicial (UCI), que contabilizaram 184 Unidades de Contexto Elementar (UCEs), distribuídas em quatro categorias: 1) "Definição de tempo livre" (40 UCEs); 2) "Uso do tempo livre" (77 UCEs); 3) "Aspectos que possibilitam a existência do tempo livre" (11 UCEs); e 4) "Realizações na possibilidade de maior tempo livre" (56 UCEs) (TABELA 2). 
Tabela 2: Distribuição das quatro categorias e 14 subcategorias

\begin{tabular}{clc}
\hline \multicolumn{2}{c}{ Distribuição das categorias de análises - 184 UCEs } & \multicolumn{1}{c}{ SUBCATEGORIAS } \\
\hline CATEGORIAS & \multicolumn{1}{c}{$f$} \\
\hline 1. Definição de tempo & 1.1 Sensação de liberdade & 13 \\
livre $(f=40)$ & 1.2 O que não é trabalho & 13 \\
& 1.3 Relações sociais & 4 \\
& 1.4 Tempo para si & 10 \\
2. Uso do tempo livre & 2.1 Tempo para si & 42 \\
$(f=77)$ & 2.2 Tempo para as relações sociais & 14 \\
& 2.3 Tempo para o lazer & 21 \\
3. Aspectos que possibilitam & 3.1 Especialidade tranquila & 1 \\
o tempo livre $(f=11)$ & 3.2 Pouca carga de trabalho/plantão & 2 \\
& 3.3 Não estar na residência & 5 \\
4. Realizações na & 3.4 Por escolha pessoal & 3 \\
possibilidade de maior & 2.1 Tempo para si & 28 \\
tempo livre $(f=56)$ & 2.2 Tempo para relações sociais & 4 \\
\hline
\end{tabular}

\section{Categoria 1 - Definição do Tempo Livre}

Nessa categoria, composta por 40 UCEs, foram apresentadas as definições dos médicos sobre o tempo livre, no que se refere à sua compreensão e/ou atividades que se relacionam ao tema.

Inicialmente, quando questionados sobre a existência ou não de tempo livre na rotina atual, os entrevistados, em sua maioria, afirmaram possuir tempo livre $(\mathrm{f}=06)$, sendo que apenas um participante afirmou não o possuir ( $\mathrm{f}=01$ ). Por outro lado, algumas ressalvas emergiram durante as respostas: sobre desejar possuir mais tempo livre $(\mathrm{f}=03)$ “Tenho, mas não na quantidade que eu gostaria" (Participante 5) e sobre possuir tempo livre muito pequeno/razoável (f=02) "Para falar bem a verdade, o meu tempo livre é muito pequeno" (Participante 4).

Percebe-se que, apesar de ressaltarem o excesso de trabalho e o pouco tempo livre disponível, os médicos participantes acreditam ter tempo livre, mesmo que relacionado às atividades básicas, como dormir, e às atividades do trabalho, como estudar. Esse fato pode ser observado na fala da Participante 7: "Tempo livre que eu 
tenho é para malhar, fazer fisioterapia e dormir". Essa ideia se distancia da definição de tempo livre proposta por Munnè (1980) e Gurgel (2017): tempo em que se deveria dedicar à satisfação das necessidades criadas pelo próprio sujeito, sem que ocorra uma necessidade externa, distanciando-se daquelas em que se tem menor autonomia, como as biológicas e as obrigatórias.

Todavia, corrobora a ideia de Chauí (1995), sobre a dificuldade de se colocar em prática o exercício da autonomia, pois ela acontece sempre em um espaço ameaçado pela heteronomia.

Já quando questionados sobre a possibilidade de existência de tempo livre na hora do trabalho, a situação mostrou-se um pouco diferente, evidenciando que quatro entrevistados responderam possuir tempo livre na hora do trabalho. Assim, consideram tempo livre o tempo em que, mesmo estando no trabalho, não estão efetivamente trabalhando, seja por um plantão mais tranquilo (Participante 6), por ter tempo para estudar, conversar ou ficar na internet no trabalho (Participante 1 e 5) ou quando um paciente falta ou atrasa (Participante 2). Por outro lado, três deles acreditam ter apenas pouco tempo livre, evidenciando a sensação de insuficiência.

Conforme apresentado na Tabela 2 a primeira categoria estabelece uma definição de tempo livre em quatro subcategorias: 1.1) "Sensação de liberdade”, que engloba os aspectos relacionados à autonomia e possibilidade de escolha, à não obrigatoriedade e ao não fazer nada - "Olha, eu acho que tempo livre é você ter a liberdade de escolher o que você quer fazer. Pode até ser não fazer nada" (Participante 5); 1.2) "O que não é trabalho", que contempla o tempo em que não se está trabalhando, como o final de semana e o período depois do trabalho - "Tempo livre é tudo o que você vai fazer que não seja trabalho, né?" (Participante 3); 1.3) "Relações Sociais", que engloba o tempo destinado aos amigos, à família e ao cônjuge - “É um final de semana 
que você vai ficar em casa curtindo com a sua família. Então, para mim, isso é tempo livre" (Participante 3); e 1.4) "Tempo para si”, que engloba atividades físicas, cuidar de si, estudar, dormir/descansar, diversão e resolver assuntos pessoais - "Resolver um assunto pessoal, alguma pendência [...] eu considero tempo livre" (Participante 6).

Observa-se, portanto, que na compreensão sobre o tempo livre, emergem mais falas nos quesitos "O que não é trabalho" ( $f=13)$ e "Sensação de liberdade" ( $f=13)$, o que pode estar relacionado à ideia de que o trabalho não representa liberdade para os participantes, principalmente pelo fato dessas duas temáticas terem aparecido, na maior parte das falas, juntas. Assim, tempo livre, para os médicos entrevistados, caracteriza-se como o que eu faço quando me sinto livre, quando não estou trabalhando.

Essa compreensão aproxima-se, em parte, da concepção de tempo livre proposta por Munnè (1980) e Gurgel (2017), que é representada pelas ações que ocorrem sem uma necessidade externa, devendo ser marcado pelo uso do tempo com total autonomia e de maneira criativa (MARTINS, 2013). Por outro lado, afasta-se, na medida em que o trabalho ou atividades relacionadas a este poderiam ser vivenciados no tempo livre. Em outras palavras: quando o tempo livre se faz um tempo preenchido por atividades relacionadas a demandas externas, sejam elas laborais ou demais obrigações. A exemplo do citado podemos tomar o caso de quando médicos utilizam seus tempos livres para estudar com fins ao exercício de sua profissão.

Assim, a percepção de tempo livre, por parte dos médicos participantes, confirma a ideia de Martins (2008, 2013, 2016, 2018), Aquino e Martins (2007) e Barbosa Junior e Baptista (2018) sobre os equívocos que o qualificativo "livre" nos remete, pois apesar de fazer alusão a uma ideia de liberdade, por outro lado, está sempre atrelado ao conceito trabalho, no momento em que o utiliza como referencial o que 
implica na percepção de que, para que o tempo livre exista é necessário não se estar trabalhando.

\section{Categoria 2 - Uso do Tempo Livre}

Apesar de acreditarem ter tempo livre, a maioria dos médicos destacou a necessidade de tê-lo em maior quantidade ( $\mathrm{f}=06)$, como se o que tivessem não fosse suficiente para realizar tudo o que desejariam. Dentre as respostas positivas, ressalta-se a resposta "Com certeza" ( $\mathrm{f}=03)$, que demonstra essa necessidade como algo notório, que não existem dúvidas.

A categoria 2 "Uso do tempo livre" é formada por 77 UCEs que caracterizam o uso do tempo livre dos médicos e divide-se em três subcategorias.

Em 2.1) "Tempo para si”, contemplou-se as temáticas relacionadas ao cuidado que o médico tem consigo mesmo, englobando a saúde, beleza, estudo, dormir, cuidar da casa, resolver coisas do trabalho e atividade físicas - No meu tempo livre, a maior parte dele eu passo em casa. E aí ou eu estudo ou eu gosto de assistir televisão. Mas quando vou assistir televisão, filme, eu procuro sair um pouco da rotina médica (Participante 5).

Em 2.2) "Tempo para as relações sociais", analisou-se o uso do tempo em consonância com as relações que os médicos estabelecem no ambiente social e contemplou o tempo destinado à família, amigos e cônjuge - "Geralmente, ou eu fico na internet, ou fico com minha noiva, ou saio para jantar, ou saio com os amigos" (Participante 4).

Em 2.3) “Tempo para o lazer” expõe-se os relatos relacionados às formas de uso do tempo livre que implicam realizar atividades relacionadas ao lazer, o que engloba saídas, jantares, ir ao shopping, viagens, entretenimento (filmes, ler livros, tocar) e ir ao 
estádio - “Aproveito muito. O lazer que eu tenho mais é frequentar estádio de futebol [...] e sempre que tem algum feriado mais prolongado, umas férias, eu tento viajar" (Participante 2).

Em relação à categoria dois, é notória a predominância do uso do tempo livre para si $(\mathrm{f}=42)$, evidenciando a tentativa desses profissionais em realizar atividades que remetam a si mesmos, em detrimento das atividades com outras pessoas. Observa-se, portanto, uma convergência com o estudo de Frasquilho (2005), que evidencia a existência de uma sobreposição da vida profissional e pessoal em detrimento da vida social, marcada pela rotina de acúmulo de horários, que faz com que, muitas vezes, se "abra mão" da vivência de tempos fundamentais dedicados ao lazer e à família.

\section{Categoria 3 - Aspectos que Possibilitam o Tempo Livre}

A categoria 3 "Aspectos que possibilitam o tempo livre" possui 11 UCEs e contempla as razões apresentadas pelos médicos como elementos que influenciam a existência de tempo livre no cotidiano. Divide-se em quatro subcategorias. Em 3.1) "Especialidade tranquila", os médicos falam como a especialidade influencia no tempo livre "Eu tenho sim, pois a minha especialidade é mais tranquila [...]" (Participante 3), 3.2) "Quantidade de trabalho/plantão" contempla a quantidade reduzida de trabalho/plantão como um desses elementos que contribui para a existência de maior tempo livre - "Tenho. Assim, como a gente na especialidade foge um pouco de plantão, então acaba que muito da carga horária não é turno fixo, por exemplo, o consultório" (Participante 2). Em 3.3) "Não fazer mais residência" os médicos falam que, apesar de terem uma carga elevada de trabalho, vivenciam uma situação melhor do que na época da residência - "Mas em média, agora, agora, depois da residência, eu tenho umas duas, três horas de tempo livre, acordado" (Participante 4). Na subcategoria 3.4) "Por escolha 
pessoal" acham que o tempo livre que possuem é resultado de um movimento de decisão concreta - "Eu tenho! Mas foi uma escolha minha. Consigo organizar exatamente pela escolha do trabalho que eu fiz" (Participante 7).

Dentre as subcategorias acima citadas, faz-se importante destacar a ideia que os médicos especialistas têm sobre a fase da residência, como um momento em que não é possível ter tempo livre. Para Nogueira-Martins (2003), a fase da residência é um momento marcado por situações estressoras relacionadas à fadiga, falta de tempo, muita responsabilidade, falta de organização pessoal, além do nível de cobrança pessoal em relação ao desempenho na residência médica.

Partindo desse princípio, a recém-saída de um período de privações, como é a residência, pode interferir na ideia dos médicos entrevistados sobre a existência de tempo livre atualmente, bem como a visão sobre a autonomia.

Além disso, ressalta-se a prevalência de falas que remetem elementos do trabalho como justificativas para a possibilidade de tempo livre em detrimento de razões pessoais e de escolha própria $(\mathrm{f}=01)$.

Evidencia-se, então, a ideia de que esta profissão, por toda sua trajetória e forma de configuração, traz consigo características próprias como, por exemplo, a dificuldade que alguns profissionais têm de destinar um tempo para o descanso, como se, de alguma forma, fosse proibido parar (GOLDENSTEIN, 2011).

Parece que hoje não se encontra mais um sentido para usufruir o tempo livre, não se sabe o que fazer com esse tempo e, muitas vezes, até existe um sentimento de culpa quando o vivencia-se, mesmo quando é uma escolha própria do sujeito.

Quando eu estou andando com médico, ou meu grupo de amigos da faculdade, eu tenho vergonha de dizer o tanto que eu trabalho, como eu estou trabalhando menos e ganhando menos. Mas quando eu estou andando com meu ciclo social que não são de médicos, eu ganho mais, e, enfim, eu sou uma pessoa normal. Eles ainda acham que eu trabalho muito. Então eu fico nesse meio mundo. E eu não sei o que é melhor (Participante 7). 


\section{Categoria 4 - Realizações na Possibilidade de Maior Tempo Livre}

Nessa categoria, composta por 56 UCEs, abordou-se o que os médicos realizariam se tivessem mais tempo livre, contemplando o que fariam a mais em relação ao que já fazem ou o que não conseguem fazer. Dividiu-se em três subcategorias. Em 4.1) "Tempo para si”, observam-se as falas dos médicos relacionadas ao tempo para a realização de atividades de ordem pessoal, englobando a saúde, exercício físico, beleza, dormir/descansar e fazer cursos - "Eu não consigo ir para a academia, não consigo ir para o inglês. São coisas que eu queria fazer" (Participante 1). Em 4.2) "Relações sociais familiares" é relatada a necessidade de um maior tempo com a família - "Ficar um pouco mais com a minha família, que eu quase não fico” (Participante 4). Em 4.3) “Tempo para o lazer" os médicos falam sobre o tempo que gostariam de ter para dedicar-se a atividades de lazer, como atividades de entretenimento (filmes, cinema, ler livros, tocar), viajar e sair - “É, eu gostaria de ter mais tempo para fazer coisas, vamos dizer, que são mais culturais, assistir um filme, ler um livro, tocar um pouco mais" (Participante 5).

A falta de cuidado para consigo mesmo entre a classe médica é evidenciada nas falas dos participantes, inclusive sobre questões relacionadas à saúde - "Estou com dor na lombar tão grande... Tu sabes que médico nunca vai ao médico, né?” (Participante 4), observando-se que, para alguns deles, essa realidade não era sequer refletida e questionada - "Achei muito interessante esse processo, ele nos faz pensar, refletir" (Participante 1).

Apesar de dedicarem a maior parte do seu pouco tempo livre para si mesmos, quando questionados "Para que gostariam de ter mais tempo livre?", recorrentes foram os relatos, relacionados a essa subcategoria, o que confirma que o tempo livre disponível e dedicado para si não é suficiente. Corrobora, assim, os estudos de Martins 
(2008, 2013, 2016, 2018), Aquino e Martins (2007) e Francileudo e Martins (2015), que evidenciam a cisão em meio a qual o homem contemporâneo se encontra: de um lado as obrigações impostas por suas atividades profissionais e, do outro, o desejo de se libertar dessas tarefas, para, assim, poder usufruir de um tempo para si.

Contempla-se que ao mesmo tempo em que o tempo livre disponível (aquele em que se está livre das obrigações laborais) é utilizado para si mesmo, o desejo de ter mais tempo livre também se relaciona à possibilidade de mais tempo para si.

Além disso, a possibilidade de maior tempo livre também emerge com a finalidade de se possuir uma vida mais tranquila e autônoma, que possibilite tempo para fazer as atividades diárias no momento escolhido, sem que seja preciso viver na correria:

[...] ter aquela sensação de não estar correndo de um lado para o outro, comer tranquilo, tomar café sentado, calmo, mastigar devagar. Diminuir a velocidade das coisas banais do dia a dia. A gente trabalha, trabalha, e as coisas banais fazemos correndo, como correr, tomar banho (Participante 5).

Já o estudo de Silva et al. (2011), contempla a subcategoria 1.2, quando apresenta como resultados da pesquisa a falta de tempo dos médicos residentes para suas necessidades pessoais, relacionadas a atividades básicas como sono e alimentação, e até mesmo para os estudos.

\section{Agenda Diária}

Foi solicitado que cada participante detalhasse um dia rotineiro, destacando as atividades realizadas a cada hora do dia, desde o momento em que acordam ao momento final do dia. Em uma análise quantitativa, os momentos marcados com menor sensação de liberdade foram: acordar, trabalhar no período da manhã e dar plantão. Por outro lado, a maior sensação de liberdade foi contemplada por: chegar em casa, dormir e fazer atividade física (TABELA 3). 
Esses índices demarcam o cansaço proveniente do trabalho dos médicos entrevistados, seja consequência de sua rotina ou da sobrecarga de trabalho, que corrobora o estudo de Cavagioni (2010), que concluiu que quase 50\% dos participantes relataram trabalhar cansados algumas vezes, decorrência da rotina extenuante de trabalho.

\section{Tabela 3: Atividades diárias dos médicos e suas percepções de liberdade}

\begin{tabular}{cc}
\hline Atividade & $\boldsymbol{f}$ \\
\hline Acordar & 1,43 \\
Plantão & 1,5 \\
Trabalhar manhã & 1,71 \\
Almoço & 2,29 \\
Trabalhar tarde & 2,43 \\
Café da manhã & 2,5 \\
Repouso & 2,67 \\
Ativ. Física & 3,67 \\
Dormir & 3,8 \\
Chegar em casa & 3,86
\end{tabular}

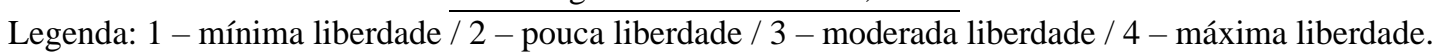

Analisando de forma subjetiva o instrumento, várias são as reflexões que devem ser levadas em consideração. O primeiro ponto que merece destaque é a atividade "Acordar", que apresentou a média mais baixa de autonomia, sendo vista como uma obrigação por todos os participantes: "Qual minha liberdade na hora de acordar? Vish! Posso colocar um zero aqui?" (Participante 4); "Nenhuma liberdade! Eu tenho que ser rápido! É tudo cronometrado! (Participante 2). Por outro lado, "Dormir” é percebido como o momento de maior autonomia: "Quando chego em casa, até eu ir dormir é liberdade máxima!'(Participante 6).

A partir desses resultados, observa-se, portanto, um distanciamento entre a sensação de liberdade, como elemento central da autonomia, por parte dos participantes da teoria proposta por Munnè (1980), pois vai de encontro ao tempo psicobiológico proposto pelo autor, que é aquele tomado e regido pelas necessidades psíquicas e 
biológicas básicas, o que aborda o tempo de dormir, alimentar-se, de atividade sexual, dentre outros, sendo esse um tempo individual que é condicionado endogenamente e, consequentemente, deveria ser marcado por baixa autonomia.

Essa distância pode ser explicada pelo fato de os médicos possuírem uma rotina exaustiva, fazendo com que a única coisa que eles precisem depois de um dia de trabalho seja uma boa noite de sono. Além do que dormir bem, muitas vezes, passa a ser um luxo, principalmente quando se remete a plantões de madrugada, como relatado por alguns entrevistados.

Apesar do ato de "Dormir" ter sido considerado um ponto com alta autonomia, percebe-se nas falas que se perde a autonomia até mesmo em relação ao horário de dormir, que passa a ser controlado e cronometrado, além de marcado por interrupções durante o período. Tem-se uma sensação de liberdade ao dormir, por parte dos entrevistados. Mas, ao mesmo tempo, esse momento é marcado por algo que "acontece quando dá”, evidenciando a ideia de heteronomia.

Percebe-se que esse cenário sobre a privação de sono, na categoria dos médicos, tem seu início ainda na formação, mais precisamente no momento da residência médica (SILVA, et al., 2011). Apesar de supostamente viverem um momento mais calmo, que possibilitaria um maior tempo livre, os médicos recém-especialistas encontram-se em um fase de tentativa de solidificação da carreira, o que indica uma multiplicidade de ambientes de trabalho, para que seja possível, posteriormente, focar-se apenas na carreira desejada, o que indicaria o alto índice proveniente de "Dormir", em detrimento do baixo relacionado ao "Acordar".

Outro ponto que merece destaque é a diferença entre a sensação de autonomia no trabalho durante a manhã e durante a tarde. Nota-se que o período da tarde promove a ideia de uma maior autonomia por parte dos entrevistados, que foi caracterizado por ser 
a hora mais perto do final do trabalho. Assim, essa ideia está intrinsecamente ligada ao resultado apresentado pela atividade "Chegar em casa", demonstrando que a sensação de autonomia, às vezes, se confunde com os espaços de tempo nos quais os entrevistados não estão trabalhando: "Quando chego em casa até dormir, a liberdade é máxima. Chego em casa 22:30, janto e durmo. Nessa hora é 4, eu cheguei em casa, é ótimo, né?” (Participante 1), "Chego em casa e janto. Eu durmo tarde. Aí a liberdade é 4, eu consigo fazer o que eu quero, me programar do jeito que eu quero" (Participante 2).

\section{Considerações Finais}

Nos tempos atuais, vive-se em uma sociedade que valoriza o trabalho e que, na maioria das vezes, despreza o tempo livre, como se fosse algo desnecessário, destinado aos que não fazem nada. Assim é a lógica do capitalismo: cada vez mais tempo para o trabalho, cada vez menos tempo para si e para os outros.

Quando se remete à classe médica, a realidade não é diferente. Talvez, pelas excessivas cargas de trabalho e múltiplos vínculos, nesse quesito seja até destaque dentre outras profissões. É preocupante saber que é motivo de vergonha poder, por escolha própria, usufruir mais tempo livre, como foi dito por um dos entrevistados.

Em momentos como esse, o exercício da autonomia pode ser prejudicado, ameaçado pelas imposições e submetido ao desejo de ganhar mais ou ter mais status entre os outros médicos. Além disso, fazem com que uma escolha própria e autônoma do sujeito acarrete sentimentos negativos, como vergonha e culpa.

Assim, parece necessário uma cisão entre tempo livre e tempo para o trabalho, o que faz com que a ideia de autonomia, como elemento central da liberdade, esteja 
sempre atrelada negativamente ao conceito trabalho, utilizando-o como referencial de inexistência.

Observa-se, pois, que, para os médicos participantes, o tempo livre só existe quando eles não estão trabalhando ou quando, em seu trabalho, encontram um tempo para fazer algo que "não é trabalho".

Percebe-se assim a dificuldade dos médicos entrevistados de verem no trabalho que escolheram para si uma possibilidade de tempo livre, o que evidencia um caráter puramente laboral. Assim, maiores são as chances do trabalho se apresentar como um elemento estressor e fatigante, distanciando-se de um momento prazeroso e autônomo.

Deste modo, a percepção de tempo livre evidencia mais ainda a confusão, ou quem sabe negação, que existe em relação a essa temática, chegando ao ponto de que sentir-se livre confunde-se com atividades básicas como dormir.

Pensando na autonomia como pré-condição para a liberdade, observa-se o prejuízo causado à sua vivência e desenvolvimento, que em tempos marcados pela sobrecarga de trabalho, multiplicidade de vínculos, falta de estabilidade e falta de tempo, faz com que os médicos se apropriem cada vez menos dela.

A percepção e a falta de tempo livre foram claramente observadas no próprio contato com os médicos participantes, no momento em que a maior parte das entrevistas $(f=06)$ aconteceu nos locais de trabalho, nas "brechas" de possíveis "tempos livres", destacando ainda o relevante número de médicos que foram contatados e não puderam fornecer entrevista em virtude da falta de tempo e/ou do tempo corrido.

Em consonância a isso, a falta de tempo aparece como fala recorrente, sendo vista como uma das inúmeras razões que geram insatisfações, principalmente no que diz respeito há um tempo para si mesmo e para a saúde, o que nos chama atenção: Como cuidar da saúde dos outros sem cuidar da própria saúde? 
Parece ser necessário trabalhos como este para que os médicos pensem e reflitam sobre sua rotina e o uso do seu tempo. Após um momento de reflexão, foi possível, a partir das perguntas e do uso do instrumento, que os médicos reconhecessem que poderiam (e deveriam) organizar-se melhor, otimizando seus tempos e rotina de trabalho.

Talvez este momento tenha sido importante por representar um momento de exercício da autonomia, colocar em ordem as prioridades, refletir sobre suas escolhas e repensar sobre o uso do tempo.

Por fim, percebe-se a necessidade de inserir na rotina, seja acadêmica, seja profissional, um momento de reflexão a respeito da sobrecarga de trabalho e a questão do tempo, relacionados à saúde e ao bem-estar desses profissionais. Mostra-se também fundamental que outros pesquisadores, sob um olhar da psicologia, adentrarem em estudos nessa área, que ainda é bastante escassa quando o enfoque é mais subjetivo e psicológico.

\section{REFERÊNCIAS}

AQUINO, C. A. B.; MARTINS, J. C. O. Ócio, lazer e tempo livre na sociedade do consumo e do trabalho. Revista Mal-estar e Subjetividade, Fortaleza, v. 7, n. 2, p. 479-500, set. 2007.

BARBOSA JUNIOR, F. W. S; BAPTISTA, M. M. Reflexões sobre a escrita como experiência aos discursos hegemônicos sobre a velhice. In: MARTINS, J. C. O.; ROCHA, L. D. L. A. (org.). No Envelhecer Experimente Viver: reflexões sobre experiências potencializadoras da vida nos tempos livres da velhice. Curitiba: Editora CRV, 2018., p. 89-124.

BARDIN, L. Análise de conteúdo. São Paulo: Edições 70, 2011

CAVAGIONI, L. C. Influência do plantão de $\mathbf{2 4}$ horas sobre a pressão arterial e o perfil de risco cardiovascular em profissionais da área da saúde que atuam em serviços de atendimento pré-hospitalar. 2010. 253f. Tese de Doutorado Universidade de São Paulo, São Paulo, 2010.

CHAUI, M. de S. Convite à Filosofia. São Paulo: Ática, 1995.

CLEVER, L. H. A saúde do médico. In: BEESON, P. B.; MCDERMOTT, W. (ed.), Cecil-Loeb: Tratado de Medicina. Rio de Janeiro: Guanabara Koogan, 1990. 
CONSElHO FEDERAL DE MEDICINA. A Saúde dos Médicos no Brasil. Brasília, DF: CFM, 2007.

CRARY J. 24/7 - A vida sem pausa. El País. 20 mai. 2015. Disponível em: http://brasil.elpais.com/brasil/2015/05/20/cultura/1432123650_805121.html. Acesso em: 22 set. 2019.

CSIKSZENTMIHALYI, M. If we are so rich, why aren't we happy? American Psychologist, v. 54, n. 10, p. 821-827, out. 1999.

DONNANGELO, M. C. F. Condições do exercício profissional da medicina na Área Metropolitana de São Paulo. Relatório de Pesquisa. São Paulo: Conselho Regional de Medicina do Estado de São Paulo, 189p, 1971.

FRANCILEUDO, F. A.; MARTINS, J. C. Sentido do tempo, sentido do ócio, sentidos para o viver. Coimbra: Grácio Editor, 2015.

FRASQUILHO, M. A. Medicina, Médicos e Pessoas: compreender o stresse para prevenir o burnout. Acta Méd Port., v. 18, p. 433-444, 2005.

GOLDENSTEIN, E. Quando os médicos des-cansam: compreendendo o sentido que médicos de um hospital público dão ao tempo livre, trabalho e lazer. São Paulo, 2011.

GURGEL, L. I. Aposentadoria e tempo desobrigado do trabalho: desvelando significados a partir de idosos ex-bancários em Fortaleza, 2017. 215f. Tese de Doutorado - Universidade de Fortaleza, Fortaleza, 2017.

HAN, B. C. La sociedad del cansancio. Barcelona: Herder Editorial, 2018.

MACHADO, M. H. Os médicos no Brasil: um retrato da realidade. Rio de Janeiro: Fiocruz, 1997.

MAGALHÃES, E. et al. Prevalência de síndrome de Burnout entre os anestesiologistas do Distrito Federal. Brazilian Journal of Anesthesiology, 2014.

MARTINS, J. C. Sentidos e possibilidades subjetivas do tempo livre. Licere, Belo Horizonte, v. 11, n.2, p.1-15, ago. 2008.

Lazeres e tempos livres, entre os ócios desejados e os negócios necessários.

Revista do Centro de Pesquisa e Formação - SESC, São Paulo, n.2, p.51-58, mai. 2016.

Ócio na contemporaneidade cansada. Revista do Centro de Pesquisa e Formação - SESC, São Paulo, Ed. Especial, p.35-44, ago. 2018.

Tempo livre, ócio e lazer: sobre palavras, conceitos e experiências. In:

BAPTISTA, M. M. (org.). O ócio nas culturas contemporâneas: teorias e novas perspectivas em investigação. Coimbra: Grácio, 2013. p. 11-22.

MUNNÈ, F. La psicosociología del tiempo libre.Cidade do México: Ed. Trilla, 1980. 
NOGUEIRA-MARTINS, L.A. Saúde mental dos profissionais de saúde. Rev. Bras. Med. Trab., Belo Horizonte, v. 1, n. 1, p. 59-71, nov. 2003.

SEGRE, M.; SILVA, F. L.; SCHRAMM, F. R. O Contexto histórico, Semântico e Filosófico do Princípio de Autonomia. Bioética, v. 6, n. 1, p. 15-23, 1998.

SILVA, G.C. et al. A importância do apoio psicológico ao médico residente e especializando em radiologia e diagnóstico por imagem. Radiol. Bras., Rio de Janeiro, v. 44, n.2, p. 81-84, mar./abr. 2011.

TRINDADE, L.; LAUTERT, L. Síndrome de Burnout entre os trabalhadores da Estratégia de Saúde da Família. Revista da Escola de Enfermagem da USP, São Paulo, v. 44, n. 2, p. 274-279, 2010.

\section{Endereço dos(as) Autores(as):}

Darli Chahine Baião

Endereço Eletrônico: darlibaiao@gmail.com

José Clerton de Oliveira Martins

Endereço Eletrônico: clerton@unifor.br

Francisco Welligton de Sousa Barbosa Junior

Endereço Eletrônico: welligtonbjr@gmail.com

Cynthia de Freitas Melo

Endereço Eletrônico: cf.melo@yahoo.com.br 